\title{
UTILIZATION OF VISIBLE LIGHT RADIATION TO DETERMINE CRACK PERCENTAGE IN SOME RICE GRAINS VARIETIES
}

\author{
G. K. Arafa ${ }^{1}$ and A. A. Abd El-Rahmam ${ }^{2}$,
}

ABSTRACT

The main objectives of the present study were to develop of an optical instrument to determine grain cracks based on numbering crack grain using a visible light radiation as the light source., and studying the effects of cracks percentage on some mechanical parameters of grains to minimize grain damage and increase rice grain quality. Grains of rice verities were Sakha 103, Yasmein Masry, Giza 101 and Giza 177. Grains with the initial moisture content of about $10.6 \%$ (b.d.), with the husk of rice grain removed by hand. The milled grains were put on screen then exposed to visible light radiation under the screen, then crack grains were counted.

The following conclusions were drawn on the basis of results of mechanical testing and light radiation examination: 1) The percentage of cracks for different grains increased with the increase of the deformation of grain, while compression strength, specific work and elasticity modules were decreased, 2) Type of grains effect on the values of mechanical parameters. Sakha 103 grain variety showed higher strength, modulus of elasticity and specific work than Giza 177 which was the lowest one., 3) Rice grain variety of Giza 177 with the moisture content of about $10.6 \%$ followed by resulting in a decrease in grain strength, modulus of elasticity and specific work by 44.75, 66.34, and 52.69\%50\% compared to the Sakha 103 . where the deformation increased by $36.84 \%$, 4) Mechanical parameters showed high correlation with the percentage of cracks. The correlation coefficient for the strength against crack percentage of grain was equal to 0.92, for the modulus of elasticity 0.99, while in the case of specific work it was equal to 0.89., 5) Resistance to cracking of grain to impacts can be advantageous on storage and biological characteristics .

1- Researcher, Agric. Eng. Res. Institute, Agric. Res. Center, Dokki, Egypt.

2- Senior Researcher, Agric. Eng. Res. Institute, Agric. Res. Center, Dokki, Egypt. 
On the other hand, high impact resistance is unfavorable in processing because of higher energy costs and less efficiency., 6) Visible light radiation method is useful for estimating seed cracking to dynamical loads., and 7) Crack testing should be continued to study the relationship between the crack value and impact site, on mechanical properties of grains, especially when using grain for industry or germination.

\section{INTRODUCTION}

$\mathrm{R}$ ice (Oryza sativa $(L)$.$) is one of the most important stable food$ crops in the world. Food habits, market price and other related factors are encouraging people to grow rice wherever water is available. Liu et al.(2005) recommended to thresh immediately after harvest. In most countries, the rice is bundled and left in the field at harvest. Leaving the rice in the field may expose the grain to dew, which re-moistens the grain. Fissures are created and cause the grain to crack when milled. Grain that is too moist will be macerated and grain that is too dry will crack during milling. Mill grain at 14 percent moisture, so adjust mill roller spacing to specific variety grain size, Improperly spaced rollers will either crack the grain or require multiple passes to de- husk the rice.

Also, they added that the quality of rice seeds has distinct effect on the yield of rice. So the proper inspection of rice seed quality is very important. At present, the identification of rice seed variety mainly depends on chemical method and paddy field method in China. Application of the chemical method is hampered by the limited amount of sample and very high expense for inspection. The cycle of inspection using the paddy field method is too long to satisfy the demand of seed circulation.

The type and range of injuries in wheat seeds caused by rotating machine elements mainly the moving parts of various technological processes harvesting, threshing, purification, transport, etc. Also, this is probably due to sudden air temperature and humidity changes during seed maturation. Corn grain's morphological and anatomical structure - size and shape, seed thickness and fruit cover, and density were discussed by Wall and Norris (1981). 
Dynamical impacts affect the internal micro-cracks in seeds (invisible to the naked eye). The number of internal micro-cracks has a significant effect on the decrease in a seed's resistance to injuries. Internal microcracks formed during maturation (temperature or humidity gradient) lower a seed's internal compactness and may reduce its dynamical strength. In turn dynamical impact may affect the increase in internal micro-cracks, according to Tye et al. (1996).

Paddy (threshed, unmilled rice), as the thermal sensitive bio-material, is apt to display degradation phenomena including cracking and inferior taste during the drying process. It is necessary to analyze and calculate the taste value of the post-drying paddy for paddy processing and dryer designing. The quality variation of post-drying paddy was studied by Bonazzi et al. (1997) .

Velupilla et al. (1990) reported that the reduction in whole kernel yield was dependent on both the rice lot and the percentage of fissured kernels. In the milling process, the grain will be broken by two causes namely; cracked kernels and non-uniformity in the final moisture content. Cracked kernel is mainly affected by the drying method, which may break rice during husking and whitening processes. A part of artificial crack is caused by thermal stress, rapid drying, moisture sorption, and high MC gradients in the drying process.

Woyniak and Styk (1996) explain that the large moisture differences between their interiors and exteriors are prone to breakage. Conditions most favorable for stress cracking occur when the grain is subjected to high temperature and non-uniform drying rates. The second factor that results in breakage is varying of final MC of paddy after drying. This factor completely is related to the height of paddy in the flat bed dryers that cause breakage during milling process due to machine strength. Also, they added that X-ray procedure enables to determine position, size and type of inner damage, and in consequence, allows to estimate the physical state of a grain which has been changed by various factors The physical state of grain endosperm influences the mechanical behavior of a grain subjected to external forces during various stages of technological processes. 
Hashemi et al. (2009) noticed that if the final moisture content has varied in the paddy layers, subsequently it could break paddy during the milling process. To overcome this problem, normally millers have increased the drying time that the difference reduces to a minimum and it results in higher crack in kernels. This problem motivated us to investigate the approach of uniform final MC in different layers of paddy by using a discharge fan to transfer the humid heated air and assessing this method at different heights of paddy when the final moisture content reaches about $8 \%$ (w.b.).

The nondestructive identification of rice seed variety on a large scale cannot be achieved by the chemical method and the paddy field method. For cases where the information must be visually obtained repeatedly and monotonously, nondestructive inspection using machine vision based on digital image processing technology is much faster. This was discussed by Richard et al. (2008).

Gunasekaran et al. (1985a) presented a descriptive account of appropriate optical methods for nondestructive quality evaluation of agricultural and biological materials. So, Optical methods have been successfully used to detect defects in biological materials.

Rittiron et al. (2004) reported technology for non-destructive measurement of single-kernel of rice attributes such as protein content, insect damage, hardness, vitreousness, and class, as well as the density and color. While some of researchs were included automated feeding and scanning, none included a means to automatically sort the kernels based on desired attributes.

Processes of heat and mass exchange that take place in the course of wheat grain wetting and drying, cause inner stress resulting in endosperm cracks. These cracks cause specific physical and biological effects, as reported by Woyniak, (2001).

Kang et al. (1995) said that the cereal grains are frequently damaged by the operation of working elements of agricultural machinery during harvest and transportation. They are also damaged during post harvest processing due to internal stresses induced by high moisture gradients occurring in the course of grain wetting and drying . 
Niewczas and Woyniak (1991) showed that the investigation on the physical state of individual cereal kernels by the X-ray technique offers a chance to examine the effect of the properties of kernel structure (inner damage of the endosperm) on its mechanical properties. Also, the X-ray procedure enables to determine position, size and type of inner damage, and in consequence, allows to estimate the physical state of a grain which has been changed by various factors

Cnossen, and Siebenmorgen (2000) mentioned that the fissures are cracks in the rice kernel, during milling, rice kernels with fissures tend to break, causing lower head and total percentages. Rice is subject to fissuring when it is below critical combinations of temperature and moisture, either in the field or after harvest. The cause of fissuring occurs when rice kernels are exposed to humidity near $100 \% \mathrm{RH}$ or water after they have dried below a critical moisture ranging between 14 to $18 \%$.

Hashemi et al. (2005) reported that the ICE has hygroscopic properties if it is moved from one environmental to another; the grain can lose or gain moisture from the surrounding environment. Farmers all over the world have increased the production of rice by adopting modern technology and efficient management techniques. However, quality and quantity losses still occur at the pre- and post harvest phases, when many factors influence the ultimate quality of grains.

Weller et al. (1990) said that the cracked kernels are characterized by reduced mechanical strength and a tendency to crumble during post harvest processing easier than grain with no such damage. Therefore, storage of the damaged grain may lead to an increased hazard of starch dust explosion in the silos. This phenomenon leads to a decrease in grain quality. So, it is very important to choose adequate parameters for the technological processes to minimize the level of grain damage and hence to decrease grain quality.

Objectives:

- To study the effects of cracks on some mechanical parameters of grains with selected characteristics obtained using visible method.

- The method could be used by grain industry to measure the quality characteristics for marketing, storage, or processing. 
- To measure some parameters for the technological processes to minimize the level of grain damage and increase rice grain quality.

- To development an optical instrument to detect various kernel cracks based on percentage grain crack through visible light vision using light radiation source.

\section{MATERIAL AND METHODS}

\section{Sample preparation}

Grains of rice were selected from the sample of Agri. Res. Center. Rice kernel samples were namely Sakha 103, Yasmein Masry, Giza 101 and Giza 177 rice grain varities. Tests were performed for 100 kernels selected randomly for any variant of the experiment, with total number of specimens of 500 grains. Grains were with the initial moisture content of about $10.6 \%$ (b.d). TThe husk rice grain was removed by hand. The milled grains were put on screen then exposed to the visible light radiation under the screen, then was number of crack grain was counted. The experiments were carried out at Process and Handling of Agric. Production Lab in Agric. Eng. Res. Institute through season 2009.

\section{INSTRUMENTS:}

Moisture content meter of grain, has the following specifications: 1) The moisture tester model is SP - 1D, 2) Manufactured by Japan, 3) Accuracy is $\mp 0.5 \%, 4)$ The power source is $220 \mathrm{~V}$, and 5) The ambient working temperature from 0 to $40{ }^{\circ} \mathrm{C}$.

Digital balance, source of manufacture: Germany; Model: SBA 51; and Accuracy $0.01 \mathrm{~g}$. It was used to determine the weight of individual grains.

Digital vernier caliper, has an accuracy of $0.01 \mathrm{~mm}$. It was used to measure the dimensions of individual grains.

Grain hardness test, hardness of the wheat kernels was tested using hardness tester (model 174886 kiya seisakusho LTD). The hardness value of each sample was recorded in kilogram and calculated in Newten.

\section{Physical properties:}

The cross-sectional area of the central part:

To calculate some of the physical properties of grains, it was should be measuring the main dimensions of grains were measurred as shown in Fig. (1). El-Raie (1987) 
The cross-sectional area, was calculated according to the formula:

$$
\mathrm{A}_{\mathrm{C}}=\frac{\pi}{16}(\mathrm{~T}+\mathrm{W})^{2} \text {----------------- (1) }
$$

where: $\mathrm{T}$ and $\mathrm{W}$ are thickness and width of the grain, $\mathrm{mm}$, respectively.

$\mathrm{A}_{\mathrm{c}}$ : the cross-sectional area of the central part, $\mathrm{mm}^{2}$

\section{Volume of grain :}

The apparent volume was calculated according to the formula: El-Raie (1987)

$$
\mathrm{V}=\frac{\pi}{6} \mathrm{LWT}
$$

where: $\mathrm{L}, \mathrm{T}$ and $\mathrm{W}$ are length, thickness and width of the grain, $\mathrm{mm}$, respectively.

$$
\mathrm{V}: \text { the volume of grain, } \mathrm{mm}^{3}
$$

\section{Visible light radiation instrument:}

For the detection of crack grain, the visible light radiation was used. The vision on light-radiation, $13 \times 18 \times 30 \mathrm{~cm}$ in size.

Light box was used by dimension, including : the operating parameters of the lamp as follows: supply voltage $220 \mathrm{~V}(50 \mathrm{~Hz})$, power 70 Watts, acceleration voltage $20 \mathrm{kV}$, current $50 \mathrm{~mA}$, visible light radiation is exposed to a varying extent by the crack and uncrack of the grains. When the light radiation beam passes through a grain, crack vision of grain is by eye. In the vision, the internal crack is visible as characteristic dark, then quantified by the number of grains cracks. Fig. 2 presents visible light radiation of kernels prepared to detect crack of grains.

\section{Cracking percentage:}

Cracking percentage of grain was calculated according to the following formula.

$$
\text { Crack, } \%=\frac{\text { Number of crack grains }}{\text { Total number of grains }} \times 100^{\circ}
$$

\section{Test of mechanical properties}

Mechanical tests were performed by a strength tester, for measuring compression and deformation. Grain was placed between two parallel plates and subjected to uniaxial compression. The force was determined in $\mathrm{N}$, and the deformation in an $\mathrm{mm}$. 
Compressive strength $\left(\sigma_{\max }\right)$, was calculated from the maximum load $\left(\mathrm{F}_{\max }\right)$ during the compression test and the average cross-sectional area $(A)$ of the grain :

$$
\sigma_{\max }=\frac{F_{\max }}{A_{C}}
$$

where: $A_{c} \quad$ : is the cross sectional area-central part of grain:mm ${ }^{2}$

$F_{\max }$ : is the compression force, $\mathrm{N}$

$\sigma_{\max }:$ is the maximum compressive stress, $\mathrm{MPa}$

The modulus of elasticity (E), was calculated from the Hooke's law:

$$
\mathrm{E}=\frac{\sigma_{\max }}{\zeta}=\frac{\mathrm{F}^{*} \mathrm{~T}_{\mathrm{o}}}{\mathrm{A}_{\mathrm{C}} * \Delta \mathrm{T}}
$$

where: $\mathrm{E}$ - modulus of elasticity, $\sigma_{\max }$ - compressive stress, $\zeta$ - strain, $\mathrm{F}$ compression force, $T_{0}$ - initial height of sample, $\Delta T$ - change in height, $A_{c}$ - cross-sectional area.

Deformation work (DW), was presented as the compression function. Deformation work depends on the sample size. In order to characterize the material itself, the notion of specific work(s $w)$ which is equal to the deformation work (DW) calculated for the unit of sample volume is determined as:

$$
\mathrm{SW}=\frac{\mathrm{DW}}{\mathrm{V}}
$$

Where:

$\mathrm{SW}$ : is the specific work, $\mathrm{mJ} \mathrm{mm}-3$

DW : is the work of deformation, $\mathrm{mJ}$

$\mathrm{V} \quad$ : is the volume of the sample, $\mathrm{mm} 3$

\section{Deformation $(\Delta T)$ :}

Deformation of grain was calculated from the following formula :

$$
\Delta \mathrm{T}=\mathrm{T}_{\mathrm{o}}-\mathrm{T}_{\mathrm{C}}
$$

where :

$\Delta \mathrm{T}:$ is the deformation, $\mathrm{mm}$

$\mathrm{T}_{\mathrm{O}}$ : is the initial thickness, $\mathrm{mm}$

$\mathrm{T}_{\mathrm{C}}$ : is the thickness after compression, $\mathrm{mm}$ 

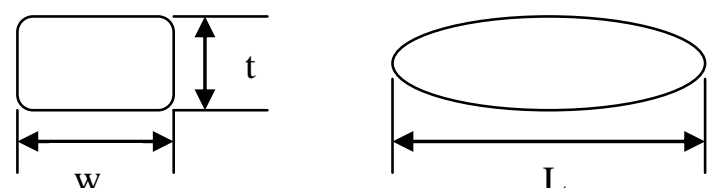

$\mathrm{L}$

Fig. 1. Main dimensions of a rice grain; $\mathrm{t}$ - thickness, $\mathrm{w}$ - width, $\mathrm{L}-$ length.

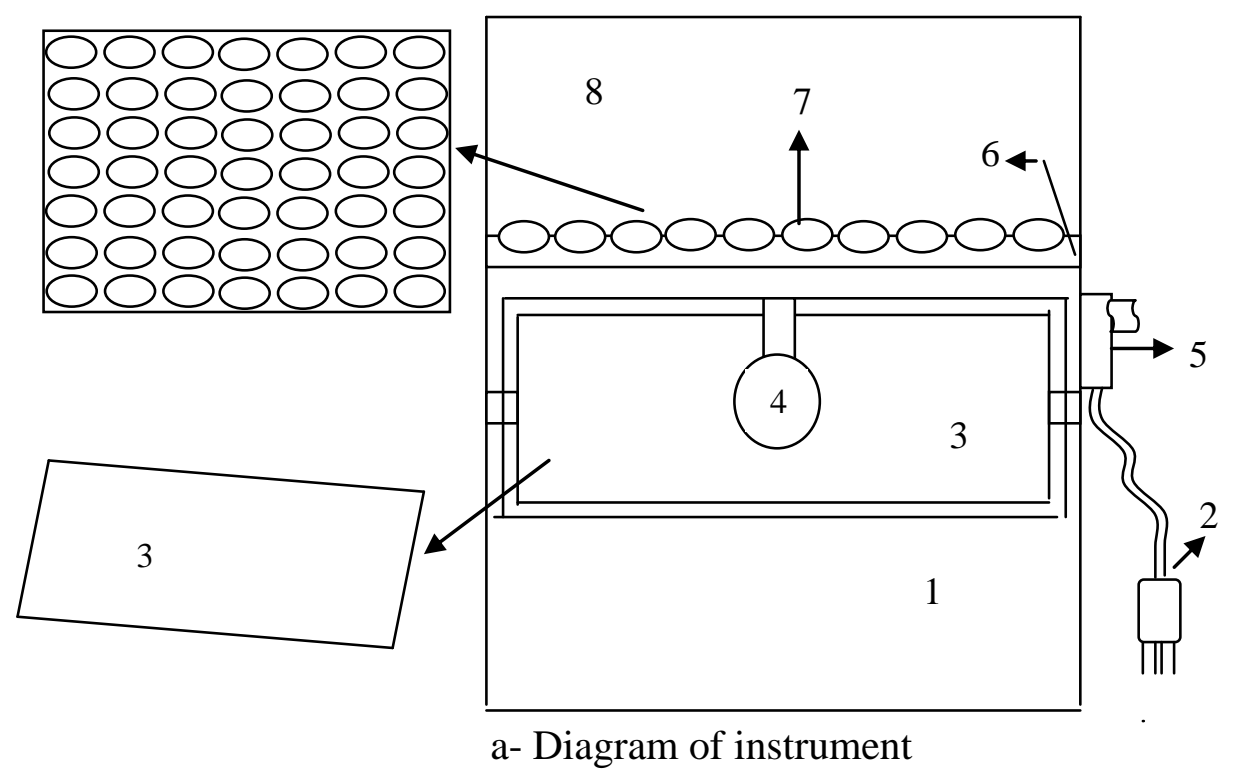

1- light box , 2- Electric source, 3- mirror, 4- light source, 5- switch, 6- screen , 7- milled rice grains, and 8-vision box.

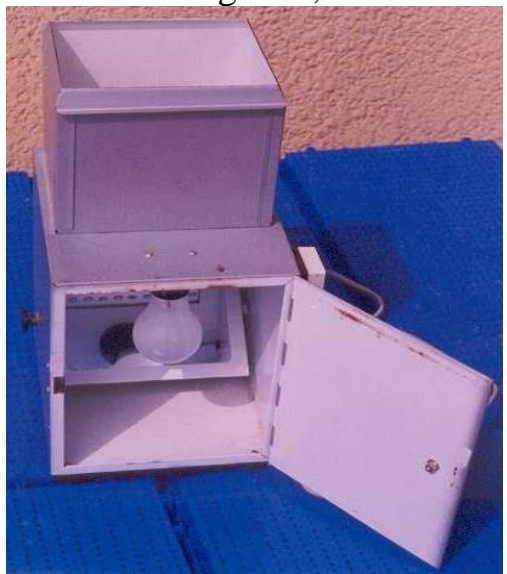

b- Photo of instrument.

Fig. 2: Diagram and photo of instrument to measure the cracking in rice milled grain. 


\section{RESULTS AND DISCUSSION}

Cereal grains are damaged by the operation of agricultural machinery during harvest and transportation. They are also damaged during post harvest processing .

Table. 1 : Some of the main characteristics of rice grains

\begin{tabular}{|l|c|c|c|c|}
\hline Items & Sakha 103 & $\begin{array}{c}\text { Yasmien } \\
\text { Masry }\end{array}$ & $\begin{array}{c}\text { Giza } \\
101\end{array}$ & $\begin{array}{c}\text { Giza } \\
177\end{array}$ \\
\hline Length, mm & 6.68 & 9.49 & 7.17 & 7.80 \\
\hline Width, mm & 2.83 & 2.40 & 2.74 & 2.92 \\
\hline Initial thickness, mm & 2.02 & 1.82 & 1.89 & 1.92 \\
\hline Mass, g & 0.030 & 0.024 & 0.020 & 0.022 \\
\hline Moisture content, \% & 10.6 & 10.7 & 10.6 & 10.7 \\
\hline Compression force, $\mathrm{N}$ & 174.2 & 125.8 & 101.6 & 095.7 \\
\hline Thickness after compression force, $\mathrm{mm}$ & 1.78 & 1.54 & 1.56 & 1.57 \\
\hline Crack, (C) \% & 4.0 & 5.0 & 6.0 & 7.0 \\
\hline
\end{tabular}

Table (1) shows some physical and mechanical parameters of different rice varieties. For physical parameters, it was noticed that the length of grain ranged between $6.68-9.49 \mathrm{~mm}$, which were $6.68,7.17,7.80$, and $9.49 \mathrm{~mm}$, the width ranged between $2.40-2.92 \mathrm{~mm}$, which were 2.40 , $2.74,2.83$, and $2.92 \mathrm{~mm}$, and thickness of grain ranged between $1.82-$ $2.02 \mathrm{~mm}$, which were $1.82,1.89,1.95$ and $2.02 \mathrm{~mm}$ and grain mass was ranged between $0.02-0.03 \mathrm{~g}$ which were $0.02,0.022,0.024$, and $0.03 \mathrm{~g}$ for Sakha 103, Yasmein Masry, Giza 101 and Giza 177, respectively.

According to main dimension of grains, the highest value was $9.49 \mathrm{~mm}$ of gain length was Yasmin Masry variety while lowest one was $6.68 \mathrm{~mm}$ for was Sakha 103 variety. The high value $2.92 \mathrm{~mm}$ for grain width was Giza 177, while lowest one $2.4 \mathrm{~mm}$ was Giza 101, and high value $2.02 \mathrm{~mm}$ of thickniss grain was Sakha 103, while the lowest one $1.82 \mathrm{~mm}$ was Yasmin Masry.

Also , for mechanical parameters., it was noticed that the moisture content of grain ranged between $10.6-10.7 \mathrm{~mm}$, which were 10.6, 10.7, 10.6, and $10.7 \%$, the compression force ranged between $174.2-95.7 \mathrm{~N}$, which were 174.2, 125.8, 101.6, and $95.7 \mathrm{~N}$, and theckiness of gran after 
compression ranged between 1.78 and $1.57 \mathrm{~mm}$, which were $1.78,1.54$, 1.56 and $1.57 \mathrm{~mm}$ and crack percentage ranged between $4-7 \%$ which were 4, 5, 6, and 7\% for Sakha 103, Yasmein Masry, Giza 101 and Giza 177 , respectively.

According to mechanical properties, the highest value $172.2 \mathrm{~N}$ of compression force for grain was Sakha, while the lowest one was $4 \%$ of grain crack for Sakha 103, while lowest value 95.7 N was for Giza 177. the highest value 7 for grain crack was Giza of grain crack was Gizza 177, while the lowest one of $4 \%$ grain crack was Sakha 103, and the highest value $1.78 \mathrm{~mm}$ thickness of compression strength of grain was Sakha, 103 while the lowest one $1.54 \mathrm{~mm}$ was Yasmein Msry.

Table 2: Mean computed values of some mechanical parameters.

\begin{tabular}{|l|c|c|c|c|}
\hline Grain type & Sakha 103 & Y. Masry & Giza 101 & Giza 177 \\
\hline Cross section area, $\mathrm{mm}^{2}$ & 4.61 & 3.49 & 4.20 & 4.59 \\
\hline Volume, $\mathrm{mm}^{3}$ & 19.97 & 21.68 & 19.42 & 23.23 \\
\hline Compression strengths, N/mm & 37.74 & 36.05 & 24.19 & 20.85 \\
\hline Specific work, N/mm & 8.71 & 5.80 & 5.23 & 4.12 \\
\hline Elasticity module, N/mm & 317.77 & 234.33 & 183.61 & 106.96 \\
\hline Deformation, $\mathrm{mm}$ & 0.24 & 0.28 & 0.33 & 0.38 \\
\hline
\end{tabular}

Table 2 presents mean values of the following parameters: percentage of cracks, the maximum stress, deformation, modulus of elasticity and specific work for the rice grains at the moisture content of grain about $10.6 \%$. It is noticed that the compressed strength of grain ranged between $37.74-20.85 \mathrm{~N} / \mathrm{mm}^{2}$, which were $37.74,36.05,24.19$, and 20.85 $\mathrm{N} / \mathrm{mm}^{2}$, the specific work ranged between $8.71-4.12 \mathrm{~N} / \mathrm{mm}^{3}$, which were $8.71,5.80,5.23$, and $4.12 \mathrm{~N} / \mathrm{mm}^{3}$, and Elasticity modules of grain ranged between 317.77 - 106.96 which were 317.77, 234.33, 183.61, $106.96 \mathrm{~N} / \mathrm{mm}^{2}$ and deformation of grains after compression ranged between $0.24-0.38 \mathrm{~mm}$, which were $0.24,0.28,0.33$ and $0.38 \mathrm{~mm}$ for Sakha 103, Yasmein Masry, Giza 101 and Giza 177, respectively. 
From the previous results, it is seen that the highest values of 37.7 $\mathrm{N} / \mathrm{mm}^{2}, 8.71 \mathrm{~N} / \mathrm{mm}^{2}$ and $317.77 \mathrm{~N} / \mathrm{mm}^{3}$ of max compressed strength, specific work, and elasticity modulus, respectively . while the lowest value of $0.24 \mathrm{~mm}$ of deformation of grain rice was Sakha 103 variety. Meanwhile, the lowest values of $20.85 \mathrm{~N} / \mathrm{mm}^{2}, 4.12 \mathrm{~N} / \mathrm{mm}^{3}$ and 106.6 $\mathrm{N} / \mathrm{mm}^{2}$ of max compressed strength, specific work, and elasticity modulus, respectively . while the highest $0.24 \mathrm{~mm}$ of deformation of grain rice was Giza 177 variety.

Also, table 2 indicate that an increases of crack percentage lead to an increase deformation and decrease of compressed strength, specific work and elasticity modules of grains. it was noticed that the increase percentage of crack were 4, 5, 6, and 7\% for Sakha 103, Yasmien Masry, Giza 101, and Giza 177, respectively while the compressed strength was decreased as $37.74,36.68,24.19$ and $20.85 \mathrm{~N} / \mathrm{mm}^{2}$ and the specific work was decrease was $8.71,5.80,5.23$, and $4.12 \mathrm{~N} / \mathrm{mm}^{3}$ and the elasticity modules was decreased as $317.77,234.33,183.61$ and $106.69 \mathrm{~N} / \mathrm{mm}^{2}$ for Sakha 103, Yasmein Masry, Giza 101 and Giza 177 rice grain varities. Therefore, rice grain of Sakha 103 variety gave higher values of compression strength, specific work and elasticity modulus, while it was less in value of deformation. But the rice of Giza 177 vareity gave less value of compression strength, specific work and elasticity modulus, while it gave high value of deformation.

\section{Effect of crack percentage on some mechanical parameters:}

Fig. 3 shows the relation between mechanical parameters and crack percentage as follows:

For compressive strength and deformation, an increase in the crack percentage from 4 to $6 \%$, followed a decrease in grain strength from 37.74 to $20.85 \mathrm{~N} / \mathrm{mm}^{3}$, for Giza 177 variety by a percentage of $44.75 \%$ as compared with Sakha 103 variety. Also, an increase of grain load compressive strength in Saka 103, compared with Giza 177, variety lead to deformation of grain which increased by percentage of $36.84 \%$ compared with Sakha 103 variety .

Modulus of elasticity, decreased from 317.77 to $106.96 \mathrm{~N} / \mathrm{mm}^{2}$ with increased creak percentage from 4 to $7 \%$. Also, an increase in crack percentage from 4 to $7 \%$ lead to increase in the deformation from 0.24 to 
$0.38 \mathrm{~mm}$, while the modulus of elasticity of Giza 177 decreased $66.34 \%$ in comparing with Sakha 103 variety.

Specific work, decreased from 8.71 to $4.12 \mathrm{~N} / \mathrm{mm}^{2}$ by increasing crack percentage from 4 to $7 \%$., The specific work of Giza 177 decreased $52.69 \%$ in comparing with Sakha 103 variety.

Also the correlation between mechanical parameters and the percentage of cracks ranged between $0.89-0.99$ which is significant and high. With the increase in the percentage of cracks, the values of kernel mechanical parameters decreased, for compressive strength, specific work, elasticity modulus, while deformation of grain increased, Fig.3.

Generally, an increase in the crack of grains resulted in a decrease of grain strength, its modulus of elasticity and specific work. The values of mechanical parameters were clearly different from grain to anther. Therefore, a decrease in the grain strength, modulus of elasticity and specific work can be associated with the increase in the grain cracking. For post-harvest processes, cracked grain is more sensitive to crushing, breaking while transported or stored.

From the previous results, the relationships are listed between mechanical parameters and crack percentages as follows:

1- The relationship between compressive strength and crack percentage is in the following equation:

$$
\sigma_{\text {max }}=-6.253 \mathrm{C}+45.34
$$

2- The relationship between specific work and crack percentage is in the following equation:

$$
\mathrm{SW}=-1.434 \mathrm{C}+9.55
$$

3 - The relationship between elasticity modulus and crack percentage is in the following equation:

$$
\mathrm{E}=-68.315 \mathrm{C}+381.46
$$

4- The relationship between deformation and crack percentage is in the following equation:

$$
\Delta \mathrm{T}=0.047 \mathrm{C}+0.19
$$




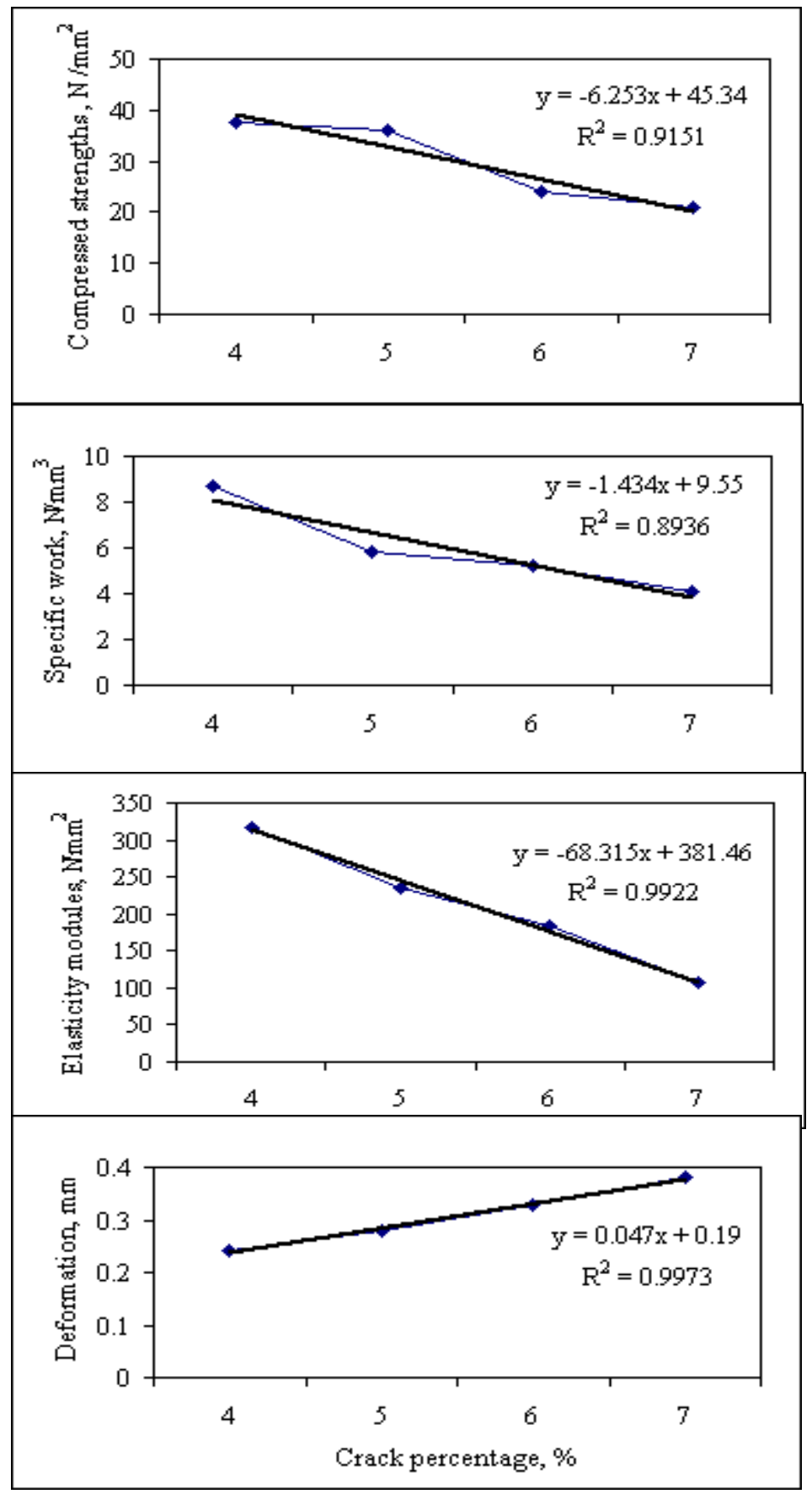

Fig. 3: Show the relation between crack percentage and some mechanical parameter of rice grains. 


\section{CONCLUSIONS}

The following conclusions were drawn on the basis of results of mechanical testing and light radiation examination:

1) The percentage of cracks for different grains increased lead to with the increase of the deformation of grain, while maximum compressive strength, specific work and elasticity modules were decreased.

2) Type of grains affects on the values of mechanical parameters. Sakha 103 grain variety showed higher strength, modulus of elasticity and specific work than Giza 177 variety which was the lowest.,

3) Rice grain variety of Giza 177 with the moisture content of about $10.6 \%$ (b.d.) resulted in a decrease in grain strength, modulus of elasticity and specific work by $44.75,66.34$, and $52.69 \% 50 \%$ compared to the Sakha 103 . while the deformation increased by $36.84 \%$,

4) Mechanical parameters showed high correlation with the cracks percentage. The correlation coefficient for the strength against crack percentage was equal to 0.92 , for the modulus of elasticity 0.99 , while in the case of specific work it was equal to 0.89 .

5) Resistance of cracked grain to impacts can be advantageous in storage and biological characteristics. On the other hand, high impact resistance is unfavorable in processing because of higher energy costs and less efficiency.

6) Visible light radiation method is useful for estimating seed cracking due to dynamical loads.

7) Crack tests should be continued to study the relationship between the crack value and impact, on mechanical parameters of grains, especially when using grain for industry or germination.

\section{REFERENCES}

Bonazzi, C., M. Peuty, and, A.Themelin. (1997). Influence of drying conditions on the process quality of rough rice. Drying Techno.15 (3\&4):1141-1157.

Cnossen, A. G, T. J. Siebenmorgen. (2000). The glass transition temperature concept in rice drying and tempering: effect on milling quality. Rice Quality Workshop 2003 Trans. ASAE 43(6):16611667. 
El-Raie, A.E.S. (1987). Properties of shelled corn related to mechanical separation. Misr. J. Ag. Eng., 4 (1) : 36-52.

Gunasekaran, S., S. S. Deshpande, M. R. Paulsen, and G. C. Shove. (1985a). Size characterization of stress cracks in corn kernels. Trans.ASAE 28(5): 1668-1672.

Hashemi J., A. Borghei, N. Shimizu, \&T. Kimura, ( 2005) "Optimization of final Moisture content of paddy in flat bed dryer with consideration of minimum losses and marketability in Iran," and Natural Reso. of Khazar, 3(2), 72-82.

Hashemi J., Reza Tabatabaekoloor, and Toshinori Kimura (2009) Effects of discharge fan on the drying efficiency in flat-bed type dryer. Proc. world acad. sci, Eng. Tec.. Volume 37 - ISSN 20703740. Pwaset Volume 37 . ISSN 2070-3740:85-87.

Kang Y.S., Spillman C.K., Steele J.L., and Chung D.S., 1995. Mechanical properties of wheat. Trans. ASAE, 38(2), 573-578.

Liu, Z. ; C. Fang; Y. Yi-bin, and R. Xiu-qin (2005) Identification of rice seed varieties using neural network (School of Biosystems Eng. and Food Sci., Zhejiang Uni., Hangzhou 310029, China). J. Zhejiang Univ. Sci. ISSN 1009-3095. 6B (11):1095-1100

Niewczas J. and Wo Ÿniak W., (1991). Application of the discretization of an X-ray picture of with grain for the evaluation of endosperm cracks. Zesz. Probl. Post. Nauk Roln., 397: 45-51.

Richard, O.; J. Michael and B. Vethaiya (2008). Integrated crop management (ICM). Dep. Trop. Plant and Soil Sci. U. Hawaii, USA and Intern. Agr. Consul., Coimbatore, India. Implementing ICM Tech. Timor-Leste , August 2008.: 5-10.

Rittiron, R., Saranwong, S., and Kawano, S. (2004). Useful tips for constructing a near infrared-based quality sorting system for single brown-rice kernels. J. Near Infrared Spectrosc. 12:133-139.

Tys J., Szwed G., Falêcki A., and fukaszuk J., 1996. Use of the dynamic method for estimation of susceptibility of rape and cereal seeds to damages (in Polish). Zesz. Probl. Post. Nauk Roln., 425: 265-268. 
Velupilla L. , \&J. P. Pandey, (1990) "The impact of fissured rice on milled yields," Cereal Chem., 1990, 67(2):118-124.

Wall G.H. and Norris E.R., (1981). A technical note on the use of a colarimetric technique for evaluation mechanical corn kernel damage. Canadian J. Agric. Eng., 23: 67-68.

Weller C.L., Paulsen M.R. and Steinberg M.P., (1990). Stress cracking and breakage susceptibility as affected by moisture content at harvest for four yellow dent corn hybrids. Trans. ASAE, 33(3): 863869.

Woyniak W. (2001). Mechanical properties of wheat grain in relation to internal cracks. Inst. Agrophysics, Polish Acad. Sciences, Dooewiadczalna 4, 20-290 Lublin 27, P.O. Box 201, Poland. Int. Agrophysics, 15: 59-64

Woyniak W. and Styk W., (1996). Internal damage to wheat grain as results of wetting and drying. Drying Tec., 14(2): 349-367.

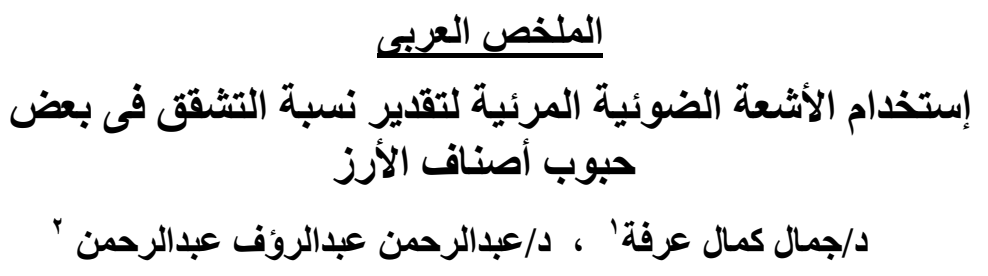

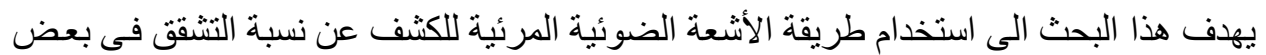

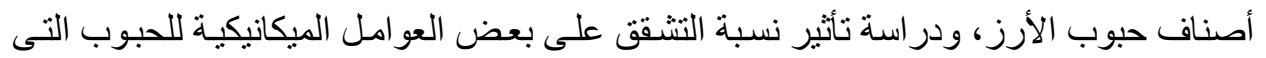

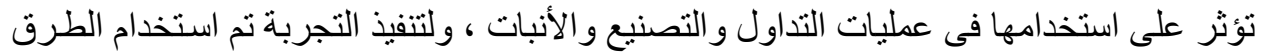

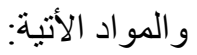

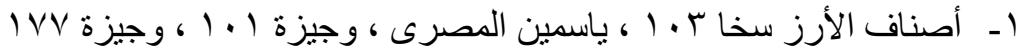

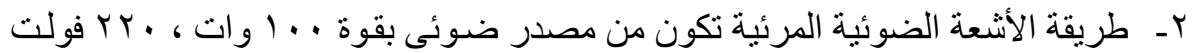

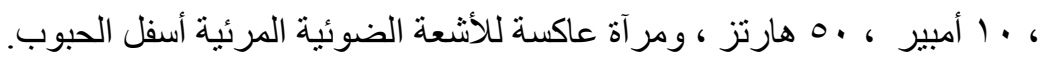

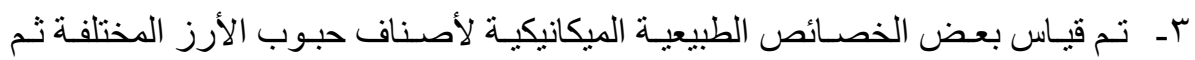

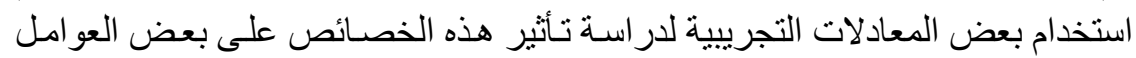

الميكانيكية التى تتعرض لها لهاد الحبوب خلال التداول و التصنيع.

1 ـ باحث أول بمعهد بحوث الهندسة الزر اعية - مركز البحوث الزر اعية ـ الدقى - مصر.

r ـ باحث بمعهد بحوث الهندسة الزر اعية ـ مركز البحوث الزية الزر اعية ـ الدقى ـ مصر. 


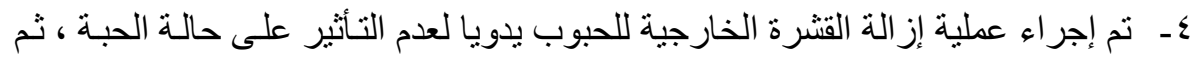

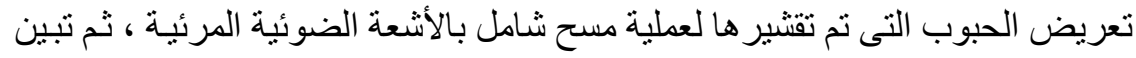

$$
\text { عدد الحبوب المشققة. }
$$

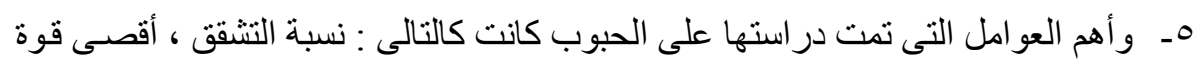
إنضغاط ، ومعامل المطاطية ، و الثغل النو عى و التغير في شكل الحبة.

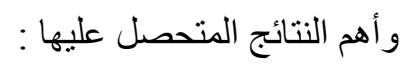

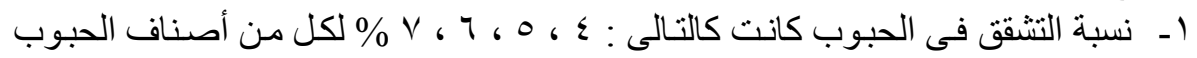

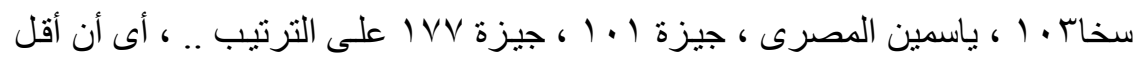

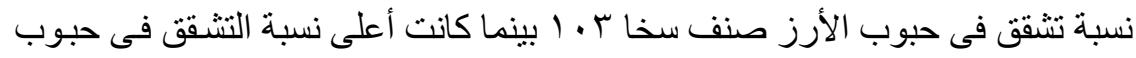

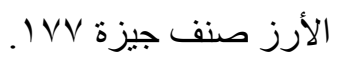

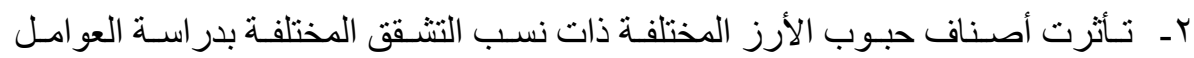

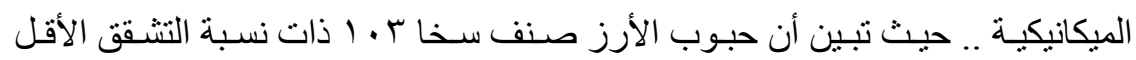

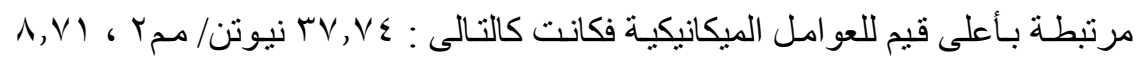

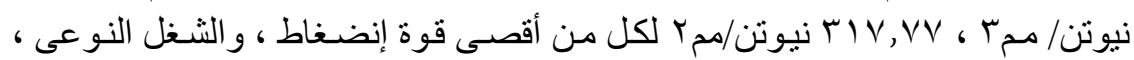

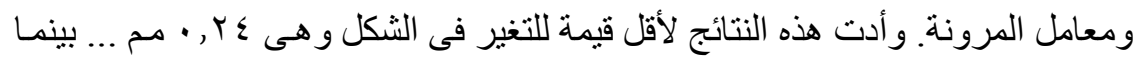

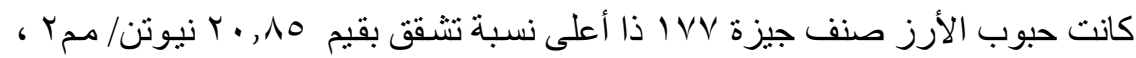

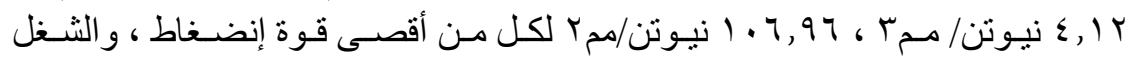

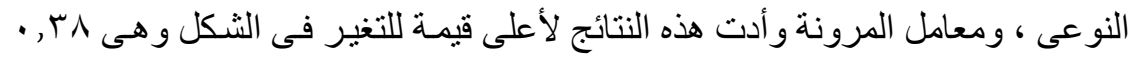

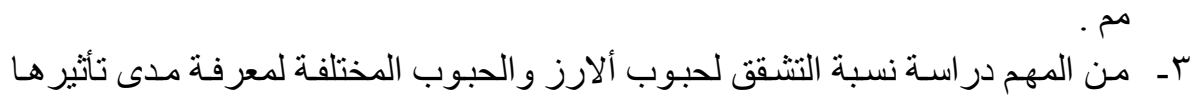

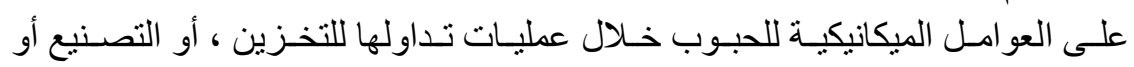

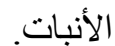

